\title{
Cutis RhomboidalisFaciei: An Early Sign of Solar Elastosis
}

\author{
Dr. Jayakar Thomas ${ }^{1 *}$, Dr. Deepthi Ravi ${ }^{2}$ \\ ${ }^{I}$ Professor\& Head, Department of Dermatology, SreeBalaji Medical College and Hospital, Chennai, India \\ ${ }^{2}$ Senior Resident,Department of Dermatology, SreeBalaji Medical College and Hospital, Chennai, \\ India \\ *Corresponding Author: Dr. Jayakar Thomas,Professor \& Head, Department of Dermatology, Sree \\ Balaji Medical College and Hospital, Chrompet, Chennai, India, Email: jayakarthomas@ gmail.com
}

\begin{abstract}
Solar elastosis is a degenerative change in the dermis occurring due to chronic exposure to electromagnetic radiation especially of the UVB wavelength. The various findings reported till now in solar elastosis include cutis rhomboidalis nuchae, Favre-Rachouchot syndrome, dermatoheliosis, popular elastosis, actinic granuloma, adult colloid milium, elastotic nodules over the ears and collagenous and elastotic plaques of the hands. We report a new finding in patients with chronic sun exposure. There was yellowish discoloration, thickening of skin and wrinkling in an irregular rhomboidal pattern over the malar area in a series of seven patients in the age group of 60 to70 years. This finding can be labeled as cutis rhomboidalis faciei. It was observed before the development of most of the other changes in solar elastosis and hence can be considered to be an early sign of solar elastosis.
\end{abstract}

Keywords:Solar elastosis, Cutis rhomboidalis, Dermatoheliosis

\section{INTRODUCTION}

Actinic elastosis also known as solar elastosis is a degenerative change in the dermis. It is caused due to chronic exposure to electromagnetic radiation most commonly solar radiation and can also be due to infrared radiation exposure ${ }^{[1]}$. UVB wavelength (290-320nm) most commonly leads to solar elastosis; however UVA (320$400 \mathrm{~nm})$ and sometimes infrared radiation $(>700 \mathrm{~nm})$ can also aggravate the condition. UVA radiation mainly leads to skin cancers. The various presentations of solar elastosis reported till now include cutis rhomboidalis nuchae, Favre-Rachouchot syndrome, dermatoheliosis, popular elastosis and sometimes actinic granuloma ${ }^{[3]}$. Here we report a new finding of solar elastosis, Cutis Rhomboidalis Faciei in which there is yellowish discoloration, thickening of skin and wrinkling in an irregular rhomboidal pattern over the malar area.

\section{CASE REPORT}

We observed a new finding in a series of seven patients coming to the Dermatology OPD. These patients had thickened yellowish skin with wrinkling in a rhomboidal pattern over the malar area (Figs. 1 and 2).
Three of the patients had cutis rhomboidalis nuchae and three had seborrhoeic keratosis. We suggest that this can be named as cutis rhomboidalisfaciei.

This finding was present even before the development of the other findings of solar elastosis such as cutis rhomboidalis nuchae in a few patients. All the patients had history of chronic sun exposure and were in the age group of 60-70 years. The histopathology was similar to that of cutis rhomboidalis nuchae and elastotic material deposition was seen in the dermis.

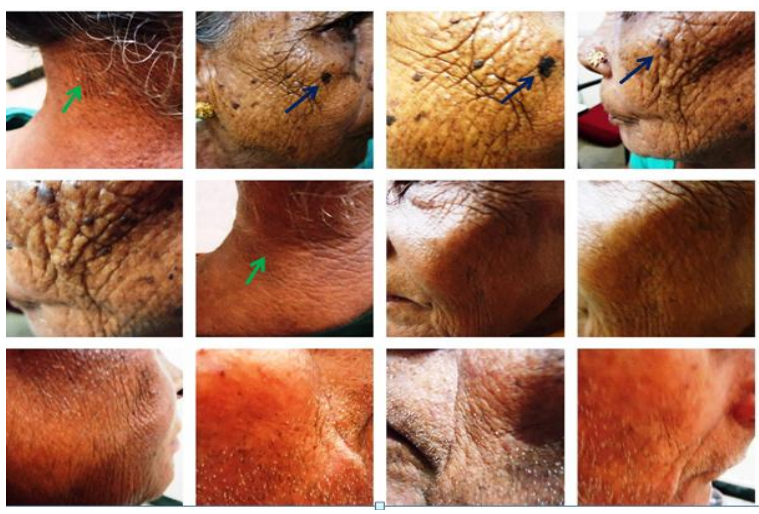

Figure1.Three patients of cutis rhomboidalis facei out of which two show cutis rhomboidalis nuchae (indicated by the green arrow) and one shows seborrhoeic keratosis (indicated by the blue arrow). 


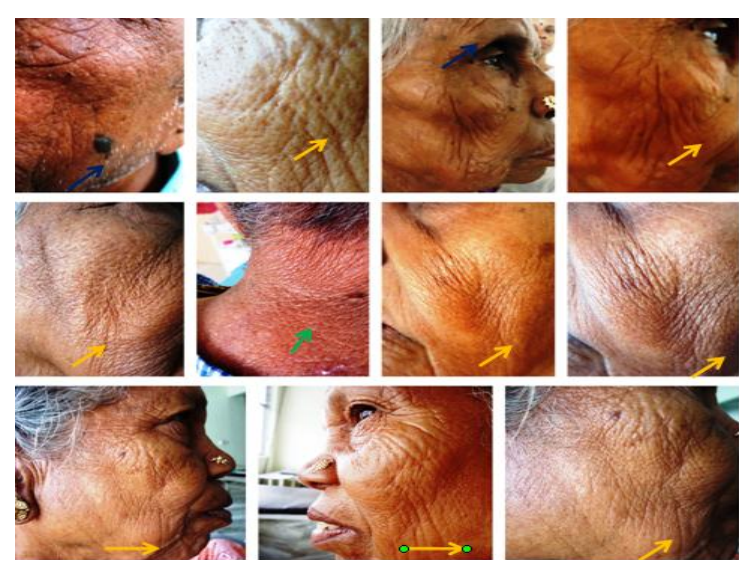

Figure2.Four patients of cutis rhomboidalis faciei out of which two patients show seborrhoeic keratosis 9indicated by the blue arrow) and one patient shows cutis rhomboidalis nuchae (indicated by the green arrow). Note the yellowish pigmentation, thickening of skin and irregular rhomboidal wrinkling of skin (indicated by the yellow arrows).

\section{DISCUSSION}

The degree of solar elastosis is directly proportional to the cumulative radiation dose and hence it is more commonly seen in outdoor workers, in elderly individuals and in people residing in sunny areas ${ }^{[2]}$. Clinically there is yellowish discoloration of the skin and there is elastic fiber degeneration histologically. The light exposed areas such as the nape of the neck and the face are more commonly affected. Mild elastosis is not visible clinically and the changes become more obvious as the skin gets pinched up and thus wrinkled. The skin tone is lost and the skin becomes coarsely wrinkled, thick and dry. Prolonged sun exposure leads to epidermal thickening and abnormalities in the dermal composition.

Cutis rhomboidalis nuchae is when the skin is yellow, thick and leathery with wrinkling in a rhomboidal pattern at the nape and the posterolateral portion of the neck. Favre Rachouchot syndrome most commonly affects the periorbital area and shows follicular cysts with thick yellow plaques and numerous open comedones $^{[4]}$. Dermatoheliosis includes changes like wrinkling, scaling, irregular pigmentation, solar keratosis and sometimes malignancy resulting from chronic sun exposure. Papularelastosis are solitary or multiple, firm, shiny, smooth asymptomatic papules ${ }^{[5]}$. Adult colloid milium ${ }^{[6]}$, elastotic nodules over the ears $^{[7]}$ and collagenous and elastotic plaques of the hands ${ }^{[8-9]}$ may also be seen.

In sun damaged skin there is degradation of elastic and/ or collagen fibers and there are overactive fibroblasts which produce new elastic tissue. Chronic inflammation is seen with degranulation of mast cells and fibroblast activation which leads to production of metalloproteinases which degrade collagen. Thus there is an abnormal degenerative and synthetic process in photo damaged skin leading to the changes observed ${ }^{[10]}$. These changes are responsible for the appearance of skin in cutis rhomboidalis nuchae and faciei.

There was an inverse relationship between cutis rhomboidalis nuchae and malignant epithelial cell tumors in a report ${ }^{[11]}$. The hypothesis being skin thickening resulting from degeneration of collagen and elastic fibers occurring due to sun exposure may play a protective role against epithelial dysplasia and thus prevent the development of neoplastic lesions. The same protective role may be present in cutis rhomboidalis faciei also due to the same mechanism. Further studies are required to confirm this; however in all the patients having cutis rhomboidalis faciei observed by the authors, there were no skin neoplasms in the affected areas.

\section{CONClusion}

Cutis rhomboidalis faciei can be considered to be an early sign of solar elastosis and should be looked for in patients with chronic sun exposure. Other solar elastotic changes may be prevented if proper photo protection is taken at this stage.

\section{REFERENCES}

[1] Burrows NP, Lovell CR. Disorders of Connective Tissue in inRook's Textbook of Dermatology Eighth Edition: 45.26 - 45.27.

[2] Pai GS, Kamath KN, Maria Kuruvilaet al. Disorders of Connective Tissue in IADVL Text book of Dermatology Third Edition: 1187

[3] Heng JK, Wee Aw DC, Tan KB. Solar elastosis in its papular form: Uncommon, mistakable. Case Rep Dermatol 2014; Jan-Apr: 6(1): 124128.

[4] Patterson WM, Fox MD, Schwartz RA. FavreRacouchot disease. Int J Dermatol 2004; 43:167-169.

[5] Kwittken J. Papular elastosis. Cutis 2000; 66: 81-83.

[6] Hashimoto K, Black M. Colloid milium: a final degeneration product of actinic elastoid. $J$ CutanPathol 1985; 12:147-156.

[7] Weedon D. Elastotic nodules of the ear. $J$ CutanPathol 1981; 8: 429-433.

[8] Kocsard E. Keratoelastoidosis marginalis of the hands. Dermatologica 1965; 131:169-175. 
[9] Burks JW, Wise LJ, Clark WH. Degenerative collagenous plaques of the hands. Arch Dermatol. 1960; 82: 362-366.

[10] Calderone DC, Fenske NA. The clinical spectrum of actinic elastosis. $J \quad A m$ AcadDermatol. 1995; 32: 1016-1024.
[11] Bonekevitch F, Souza PRM. Cutis rhomboidalis protects skin from malignant epithelial tumors. Medical Hypotheses 2014; 82:652-653.

Citation: Dr. Jayakar Thomas, Dr. Deepthi Ravi. Cutis Rhomboidalis Faciei: An Early Sign of Solar Elastosis ARC Journal of Dermatology. 2017; 2(2):1-3. doi:dx.doi.org/10.20431/2456-0022.0202001.

Copyright: (C) 2017 Authors. This is an open-access article distributed under the terms of the Creative Commons Attribution License, which permits unrestricted use, distribution, and reproduction in any medium, provided the original author and source are credited. 